\title{
A Rare Case of Tarceva Resulting in Tympanic Membrane Necrosis
}

\author{
Michele M. Gandolfi, Ana H. Kim \\ Department of Otolaryngology, New York Eye and Ear Infirmary, New York, USA \\ Email: mgandolfi@nyee.edu
}

Received May 2, 2013; revised June 3, 2013; accepted June 18, 2013

Copyright (c) 2013 Michele M. Gandolfi, Ana H. Kim. This is an open access article distributed under the Creative Commons Attribution License, which permits unrestricted use, distribution, and reproduction in any medium, provided the original work is properly cited.

\begin{abstract}
Objective: To report a novel case of Tarceva ${ }^{\odot}$ treatment for small cell lung carcinoma resulting in tympanic membrane necrosis. Patient: A 49-year-old male with tympanic membrane necrosis and presumed resistant acute otitis externa and chronic inflammation of the left ear. Patient is status post chemotherapy and radiation diagnosed with non-small cell lung cancer in December 2008 with on-going therapy with Tarceva ${ }^{\odot}$ for residual disease. Intervention: Tympanoplasty of left ear. Results: Improvement of symptoms of irritation and improvement of hearing and speech reception thresholds. All acid fast bacilli, fungal and bacterial cultures of the intra-op specimen were negative. Conclusions: The possibility that long term Tarceva ${ }^{\mathcal{O}}$ therapy could have caused the tympanic membrane necrosis and acute otitis media like symptoms is feasible since $\operatorname{Tarceva}^{\mathcal{Q}}$ is an inhibitor of epidermal growth factor receptor (EGFR) tyrosine kinase. Upon activation of EGFRs it undergoes a transition from inactive monomeric form to active homodimer or hertodimer with another member of the ErbB receptor family. This then initiates several signal transduction cascades, leading to DNA synthesis and cell proliferation. Activation of the receptor is important in the innate immune response in human skin. Some of the common side effects include an aceiform skin rash but this is the first reported link between tympanic membrane necrosis and Tarceva ${ }^{\circ}$.
\end{abstract}

Keywords: Tympanic Membrane Necrosis; Tympanoplasty; Tarceva $^{\odot}$

\section{Introduction}

Tympanic membrane (TM) necrosis can result from many etiologies including infection, toxins, medications or a foreign body in the external auditory canal (EAC). There are many reports detailing instances where a button alkaline battery placed into the EAC has caused both EAC liquefaction necrosis and TM necrosis [1-3]. This is one true otolaryngological emergency necessitating immediate attention. Virulent strain of group A streptococcus associated with acute otitis media or otomycosis in immunocompromised hosts resulting in TM necrosis have also been reported [4,5]. Lastly, TM necrosis has been linked to osteonecrosis from radiation in patients with breast and prostate cancer, and multiple myeloma [6,7].

In each of these instances the tenuous blood supply to the tympanic membrane has been compromised. The compromise can be caused by various etiologies such as destruction by an alkaline environment, over growth of virulent bacteria or by radiation. Whatever the cause of necrosis the treatment is always to eradicate the source by removing the foreign body, treating the infection and restoring blood flow to remaining membrane and removal of necrotic tissue. Additional goals are to reconstruct anatomical components that were destroyed and restore hearing. This is the first case report implicating TM necrosis with Tarceva ${ }^{(}$(Genentech, San Francisco, CA), an inhibitor of the human epidermal growth factor receptor (EGFR), used commonly for maintenance therapy, as well as second- or third-line therapy in advanced nonsmall cell lung cancer (NSCLC) [8].

\section{Case Presentation}

The patient is a 49-year-old male, who was referred to our Otology clinic after failing treatment for presumptive left otomycosis in February, 2012. He reportedly lost his hearing at 5 years of age on the right and the left ear was his only hearing ear. The patient reported that ever since undergoing chemo and radiation therapy for NSCLC in 2008 , with subsequent ongoing therapy with Tarceva ${ }^{\circledR}$ for residual disease, he developed diffuse skin erythema, 
especially involving his face. On physical exam, the only notable finding was the TM necrosis on the left with a $25 \%$ central perforation. Patient denied otalgia or otorrhea from this ear. Acid-fast bacilli (AFB) and mycotic cultures were negative of the necrotic TM. Pathology revealed necrotic debris only. Audio showed profound sensorineural hearing loss (SNHL) on the right, and mild sloping to severe SNHL on the left, with a speech recaption threshold of $55 \mathrm{~dB}$ and word recognition score of $90 \%$. Temporal bone CT showed no bony erosion, but a rind of abnormal soft tissue opposing the remnant TM.

Patient presented a month later, now with a 50\% TM perforation (Figure 1(a)). Patient elected to undergo tympanoplasty to prevent worsening of his only hearing ear. Intra-operatively, once the necrotic TM was removed and the tympanomeatal flap elevated to expose the middle ear, there were necrotic debris adherent to the promontory (Figure 1(b)). Once this was scraped off, healthy intact otic bone was noted. Post-op course was unremarkable, and the fascia graft remained intact (Figure 2) by 4 months post-op. Final pathology from the intra-op specimens reported necrotic debris, and microbiology showed no growth on AFB and fungal cultures (Figure 3).

\section{Discussion}

Clinical trials have shown that treatment with Tarceva ${ }^{\circledR}$

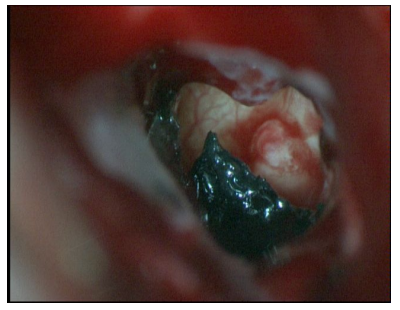

(a)

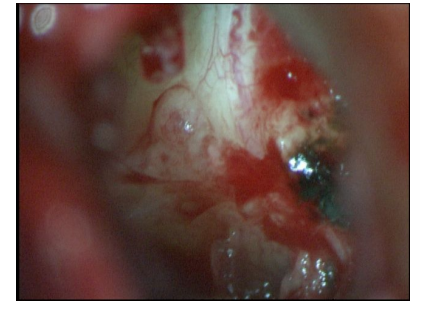

(b)
Figure 1. Left TM necrosis (a) involving the inferior and anterior quadrants. After removal of nectrotic TM and elevating the tympanomeatal flap, necrotic debris is noted on the promontory (b).

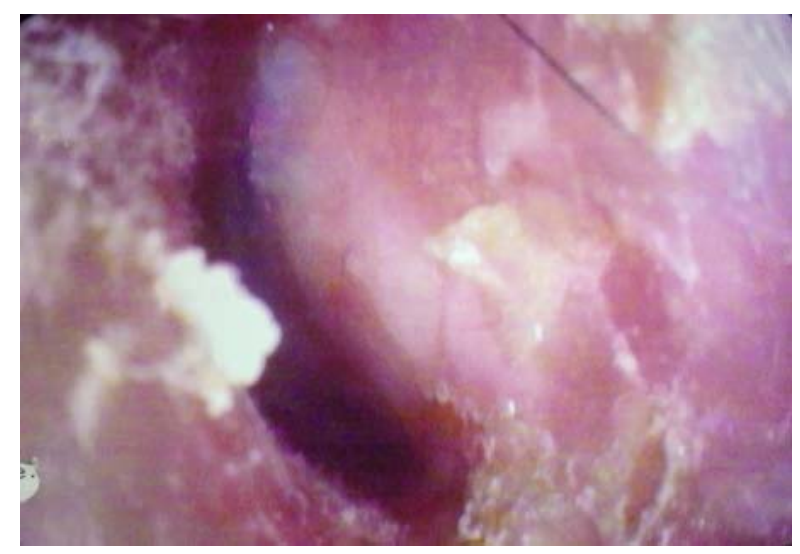

Figure 2. Healed tympanic membrane 4 months post-op.

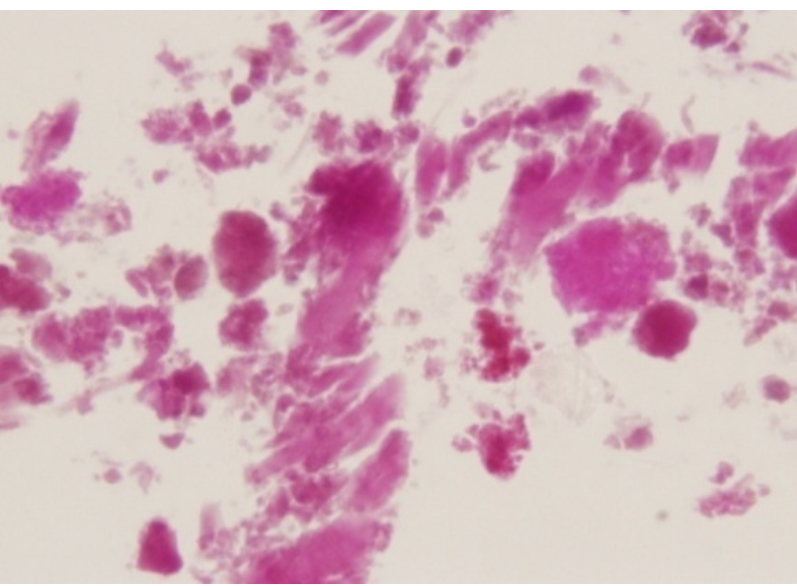

Figure 3. H \& $\mathrm{E}$ of the intra-op specimen showing eosinophilic necrotic debris.

for patients with advanced non-small cell lung cancer had a median survival time of one month longer than those who took placebo and had a $29 \%$ reduction risk of their cancer advancing or causing death [8]. The possibility that long term Tarceva ${ }^{\circ}$ therapy could cause tympanic membrane necrosis and acute otitis externa like symptoms is feasible since Tarceva ${ }^{\odot}$ is an inhibitor of EGFR tyrosine kinase. Epidermal growth factor receptor exists on cell surfaces and is activated by ligands including epidermal growth factors and transforming growth factor alpha.

Upon activation of EGFR, it undergoes a transition from inactive monomeric form to active homodimer or heterodimer with another member of the ErbB receptor family. This dimerization stimulates its intrinsic intracellular protein-tyrosine kinase activity. As a result, autophosphorylation of several tyrosine residues on the C-terminal domain of EGFR occurs. This autophosphorylation elicits downstream activation and signaling by several other proteins that associate with phosphorylated tyrosines. This then initiates several signal transduction cascades, leading to DNA synthesis and cell proliferation. Activation of the receptor is important in the innate immune response in human skin. EGFR tyrosine kinase inhibitor's role in cell proliferation is why Tarceva ${ }^{\circledR}$ has yielded its good clinic response as maintenance therapy or $2 \mathrm{nd} / 3$ rd line cancer treatment.

The most common side effects of Tarceva ${ }^{\circ}$ are formation of an aceiform skin rash and diarrhea [9]. Less often, it can cause fatigue, nausea and skin dryness and cracking. In some Asian patients or in patients who have received a great deal of radiation to the chest, it can cause a life-threatening inflammation of the lungs or interstitial lung disease [10]. However, this is the first report of TM necrosis. The direct etiology of the TM necrosis is unclear, but it is possible that the integrity of the EAC/TM epithelium can be compromised on long term 
$\operatorname{Tarceva}^{\odot}$ therapy due to impeding cell proliferation by similar mechanisms that blocks cancer cell growth.

\section{REFERENCES}

[1] D. J. Premachandra and D. McRae, "Severe Tissue Destruction in the Ear Caused by Alkaline Button Batteries," Postgraduate Medical Journal, Vol. 66, 1990, pp. 52-53. doi:10.1136/pgmj.66.771.52

[2] T. P. Votteler, J. C. Nash and J. C. Rutledge, "The Hazards of Ingested Alkaline Disk Batteries in Children," Journal of the American Medical Association, Vol. 249, No. 18, 1983, pp. 2504-2506. doi:10.1001/jama.1983.03330420050034

[3] J. C. Houck, L. DeAngelo and R. A. Jacob, "The Dermal Chemical Response to Alkali Injury,” Surgery, Vol. 51, 1962, pp. 503-507.

[4] B. Viswanatha and K. Naseeruddin, "Fungal Infections of the Eat in Immunocompromised Host: A Review," Mediterranean Journal of Hematology and Infectious Diseases, Vol. 3, No. 1, 2011, Article ID: e2011003.

[5] T. Kanazawa, H. Hagiwara and K. Kitamura, "Labyrinthine Involvement and Multiple Perforations of the Tympanic Membrane in Acute Otitis Media Due to Group A
Streptococci,” Journal of Laryngology \& Otology, Vol. 114, No. 1, 2000, pp. 47-49. doi:10.1258/0022215001903654

[6] E. L. Slattery, T. E. Hullar and L. R. Lustig, "Purulent Ororrhea: Radiation Induced Chronic Otitis Externa,” In: M. Stewart and S. Selesnick, Eds., Differential Diagnosis in Otolaryngology Head and Neck Surgery, Thieme, 2010.

[7] L. F. Fajardo, M. Berthrong and R. E. Anderson, “Organs of Special Senses: Ear,” In: Radiation Pathology, Oxford University Press, New York, 2001, pp. 409-411.

[8] A. Gardner, "Tarceva Battles Lung Cancer in Some," Health Day News, 22 July 2011.

http://health.usnews.com/health-news/family-health/cance r/articles/2011/07/22/tarceva-battles-lung-cancer-in-some

[9] D. Eisele and R. V. Smith, "Chemotherapy in Head and Neck Cancer,” In: Complications in Head and Neck Surgery, 2nd Edition. Mosby Elsevier Inc., Philadelphia, 2009.

[10] A. Ko, M. Dollinger and E. Rosenbaum, "Everyone's Guide to Cancer Therapy,” 5th Edition, Andrews McMeel Publishing, LLC, Kansas City, 2008. 